\title{
Migration and human rights - challenges and possibilities
}

\author{
by Ulrich Karpen
}

$\mathrm{T}$ his article considers issues relating to migration and human rights, and begins by considering two case studies:

\section{CASE STUDY 1}

A medical doctor - a migrant from an Arab country described a recent encounter with the Police President of his city in a West-European country:

"There was a phone call from the Police President. He asked for dialogue. I did not understand what he wanted. He repeatedly said 'dialogue' - why didn't he simply say: 'I want to talk to you'? But alright, he wants dialogue; he did not mention a topic, and I answered: 'Of course - we would enjoy a visit from you.' A Police President is not anybody, you understand. He insisted on making an appointment. I said: 'I am retired. I am at the mosque almost every day, Wednesday, Friday and Sunday under all circumstances. Come, if you have time.'

"He talked lengthily, I cannot recall everything, and finally he asked sort of timidly: 'We would like to start a dialogue with the whole Muslim parish or community; maybe a Friday, before or after prayers, would be appropriate?' Well - who is 'we'? The police? And who is the 'Muslim parish'? Our community holds 30 to 40 retired people, all of whom are Arab doctors or engineers. Some are from Turkey or Iran. Of course, I don't have any objections to such a meeting. He should come Friday at 6pm, I said.

"Then it became embarrassing. He talked and talked, and we always heard 'dialogue'. It was painful because none of the 25 old men present understood what he wanted. I asked him bluntly what the conversation was about. He revealed that he would like to have a dialogue with young people who cause trouble around the mosque. 'What do we have to do with that?' we asked. And again he said: 'Dialogue with Muslims, there has been no such dialogue for a long time. Dialogue to improve common life, friendship.'

"I remained polite, police are important and I respect - of course - a Police President. But at one point I had to say: 'None the people who sit here has a problem with dialogue. Nobody does bad things, we all pay our taxes, have employees from this country and our kids have diplomas from the city university.' I added: 'Those young people he referred to have been insolent and cheeky to us as well. They are not Muslims, and they don't go to mosques, particularly not to ours.' And another member of the group made clear to the policeman that we ourselves are afraid of these young rowdies. Another added that one cannot make a dialogue with such people; they should be imprisoned, that's it. I think that is necessary for some of them. How can we make the police do their job?"

\section{CASE STUDY 2}

According to the standing rulings of the European Court of Justice in Luxemburg, European citizenship is the "basic status of citizens of EU Member States.” The court made decisions in 2010 which widened the rights of individuals emanating from EU citizenship. This development reached a peak in a judgment of the Great Chamber of the court in March 2011. The essence of this judgment is the discovery of a core of EU citizenship, which could be claimed also from the nation state. This is a new development; the case concerned, Zambrano $v$ Office national de l'emploi (ONEm) (C-34/09), is examined below, and some conclusions drawn from it.

\section{The Zambrano judgment}

Ruiz Zambrano and his wife - both Colombian citizens - lived in Belgium from 1999 with insecure legal status after an unsuccessful asylum procedure. Applications made by the couple to legalize their stay failed. Mr Zambrano worked illegally. During their stay, two children were born. The couple omitted to apply for Colombian citizenship for their children - obviously on purpose. According to Belgian law, the children became Belgian citizens in order to avoid statelessness. On submission of the case to the European Court of Justice by the Tribunal du Travail of Brussels, the ECJ granted Mr Zambrano a right to legalize his status and an entitlement to a work permit.

The court derived Mr Zambrano's right from the EU citizenship of his children (Art 20 of the Treaty on the Functioning of the European Union). The ECJ argued that denying Mr Zambrano the right to stay would have the consequence that the children - both of them EU citizens - would be forced to leave EU territory in order not to be separated from their parents. If so, the core of EU citizenship of the children would be destroyed. In other words, third country foreigners who live illegally in Europe may stay if their child is an EU citizen and they pay for 
his/her maintenance. This is true even if - as in this case the EU citizen never left the country of stay (Belgium).

This is new because according to former decisions of the ECJ, EU citizenship came into effect only when the person left the home country in order to stay or to settle in another Member State. The consequence of EU citizenship was to open national borders for citizens of other Member States, basically in order to facilitate trans-border migration. During the court proceedings national governments of nine Member States argued that it was not an EU law case but a purely national matter (for Belgium). Without going into too much detail, it can be said that national law concerning foreigners would be set aside if protection by EU citizenship is granted in such national matters to foreigners from third states. The legislators of the Member States would be deprived of their competence to regulate the admission and stay of citizens of third states according to their own options.

\section{ANALYSIS OF THE TWO CASE STUDIES}

It is submitted that the two case studies set out above shed light on some of the factual and legal problems of migration. They will now be analysed using a three-step approach:

1. By presenting some facts concerning migration in Europe.

2. A brief overview of the human rights topics of migration.

3. By drawing attention to some shortcomings relating to the migration situation in Europe and suggesting some instruments to improve it - ie challenges and possibilities

\section{Definitions, data, facts}

Migration means - as we all know - that a person transfers the centre of his/her life and work to another place. But in our context we mean transnational migration within the European Union, and international migration, the latter by citizens of states which are not EU Member States (ie third states). In dealing with the issues presented by migrants - integration, naturalization, rights and duties we need, however, to encompass a larger group.

The term for this group is "people with migrant background". These are not only the migrants themselves, but also young persons who have been born in a EU Member State and have at least one parent who comes from another Member State or from a non-European state. They mostly have no migration experience themselves and often are naturalized. The legal situations of migrants differ from country to country in Europe, but the basics are similar. In a globalized world, migration is a ubiquitous phenomenon, and it will certainly grow. Those living in Europe and within the union should consider themselves privileged to live in a continent which is the goal for so many migrants from all over the world, and offers them aspiration and hope.
Some statistics are appropriate here. The 27 Member States of the European Union have a total population of half a billion people, which includes some 20 million nonEuropean citizens and approximately 60 million migrants. Germany, with a population of 80 million, is home to 16 million people with a migration background, half of them with German citizenship. Of the remaining 7.5 million or so migrants, 2.3 million come from EU Member States. Hamburg (the author's home city) has 1.8 million inhabitants, of which one third $(510,000)$ have a migration background with 223,000 not holding citizenship. As in all other countries the majority of people with migration background are young. Migrants come from all over the world, in Europe from Turkey, Afghanistan, Iran, and Serbia amongst other places. In Hamburg, 18 per cent of the migrants are from Turkey, and 13 per cent from Poland. In Bergedorf - one of the city's seven districts -7 per cent of the population has a Polish background

There is general agreement that the goal of society and government is to achieve a migration policy that brings social integration in the sense that unity in diversity can be achieved. This is the main idea of building Europe, as spelled out in Article 3 of the Lisbon Treaty. How could that be different in Member States? It means that only one out of four possible models is qualified to further peaceful coexistence with co-citizens having a migration background. A society must evaluate the possibilities and dangers presented by the following concepts:

- inclusion (establishing a multi-cultural society);

- assimilation (leading towards homogenity);

- separation (exclusion of parts of society which may lead to parallel structures within society);

- marginalization (creating minorities and causing isolation of individuals).

All these possible approaches have been tried historically and actually find support in our political sceneries. I think, however, that integration in plurality is the best way: "Let's enjoy our similarities and celebrate our differences."

But which data should be used to evaluate integration processes and results? Which are the core indicators, the common set of values to measure progress against and monitor policy? Which are the fields of more successful and less effective integration?

Mention should be made first of the world of economy. To find a job, to earn one's own money, to be independent is a basic goal for any individual. Occupational integration requires education. Does it really matter if some politicians hypocritically advocate integration as humanistic behaviour when they really mean that in our particular demographic situation we need a young work force? Here we need heroes, such as Vural Öger, the politician of Turkish descent who rose to become a German MEP.

The second field of integration is of course culture in the widest sense. The under-representation of young people 
with a migration background is dramatic. To learn the language of the country, its social values, its discipline is essential for fruitful coexistence. This includes mandatory participation in sports and swimming for all boys and girls. The Shador fortunately is no longer a problem, whether you interpret it as a cultural, fashion, religious or political expression of personality. In most European countries the Burka is not used. We need heroes in culture, like Lukas Podolski, the Polish-born footballer who has played for the German national side.

Even more important is the social sphere. The single most important factor of integration is the family, and not just according to the subsidiarity principle, which is an element of the Lisbon Treaty. Family, friendship, and partnership are at the core of successful or failed integration. Strongly deviating cultural habits like honour killings, forced marriages or violence as a "tool of communication" cannot be tolerated. Finally, it is essential that people with migration background participate in political and civic matters: be it in elections (as far as constitutionally manageable), in political parties, unions, or in consultative bodies. There is a constitutionally-based right to receive information about available rights to join the political and civic world and co-decide. We have heroes: the first minister with a Turkish background in Lower Saxony, and Cem Özdemir, as chairman of the Greens. We know that people with a migration background participate not less, but differently in society: not so much in Parliaments, parties, unions, but more in sports clubs, and in streetsociety life.

All these efforts to support integration, mainly from a person's own sources and powers, run towards the final goal: emotional integration. Personal integration has psychological, social and cultural elements. Who am I? Where do I stand? Some people with a migration background, old as well as young, do not know which national and cultural identity they belong to. They are "sitting between chairs". It is sort of a hybrid identity, which a German with Arab roots put like this: "If I say, I am a German, but not like the Germans, and Moroccan, but not like a Moroccan - this is for my partners a riddle."

\section{Human rights as instruments to protect migrants and enable integration}

"All human beings are born free and equal in dignity and rights. They are endowed with reason and conscience and should act towards one another in the spirit of brotherhood."

Are the these words - Article 1 of the Universal Declaration of Human Rights (1946) - "solemn affirmations lacking in sense", are they "outdated", are they "law in the books" or "law in action"? The situation of people with a migration background is indeed a field where their validity and strength can be tested. All the legal instruments which this article will refer to shortly strive at guaranteeing justice for migrants by protecting their dignity, combating discrimination, and opening the gate to asylum. Every country has to check whether its legal order stands the test of migration, considering whether sovereignty steps back sufficiently to allow for solidarity with migrants as a command of justice.

We have human rights, applicable for migrants on an international, supranational and national levels. The legal predecessor of the Universal Declaration of Human Rights (1946) is the Charter of the United Nations (1945). In its preamble it stresses that it aims at reaffirming "faith in fundamental human rights, in the dignity and the worth of the person, in the equal rights of men and women of nations large and small”. One has to add the International Covenants on Civil and Political Rights and on Economic, Social and Cultural Rights (1966) as well as the Conventions Against all Forms of Racial Discrimination (1965), relating to the Status of Refugees (1951 - Geneva Refugees' Convention). There is also the work of the UN Special Rapporteur on Human Rights of Migrants, who started global campaigns promoting the improvement of migrants' situations, and that of the UN General Assembly, which launched world conferences against racism and xenophobia. Amnesty International, with its access to media, is a global player in monitoring the implementation of human rights of migrants, and the growing activity and visibility of the International Criminal Court (ICC) in The Hague fosters information about, and prosecution of, violations of migrants' rights.

On the supranational and regional levels we have to distinguish the European Convention of Human Rights of the Council of Europe (1950) from the Charter of Fundamental Rights of the European Union (2000/2007). The Convention and its many protocols is so strong because it is enforced by the European Court of Human Rights, which grants access not only to Member States but to every individual. It is a "lighthouse" of transparency and the implementation - or lack of it - of human rights. Moreover, there are the European Conventions on the Participation of Foreigners in Public Life at Local Level (1992) and on the Legal Status of Migrant Workers (1977) as well as the Social Charter (1991). The European Convention on Nationality (1997) codifies principles and rules covering all aspects of nationality, from facilitating acquisition by long term-residents and recovery by former nationals to limiting grounds for withdrawal and statelessness.

The Charter of Fundamental Rights of the European Union is not law in force, since it has not been ratified by all Member States. Article 6 of the Lisbon Treaty, however, reads as follows: "The Union recognises the rights, freedoms and principles set out in the Charter of Fundamental Rights of the European Union ..., which shall have the same legal value as the Treaties." The Charter covers more or less the same rights as the other legal instruments referred to above. It is, however, a significant step forward in quality, since the scope of the format of the 
rights and their dogmatic structure represent the progress of the interpretation of human rights made by the courts, lawyers and academia.

As regional source of human rights, one might take into account the Nordic Union Code and the Charter for a New Europe of the Organization for Security and Cooperation in Europe (OSCE, 1990). It is a result of the Helsinki Process, which already in 1975 assured its respect for human rights, the reunification of families through the participating states. By the way, OSCE's Office for Democratic Institutions and Human Rights (ODIHR) is located in Warsaw.

Finally, there are the fundamental rights codes contained in most Member States' constitutions and in federated systems in sub-national constitutions as well, including Constitutional or Supreme Courts to apply the rights on the appropriate level.

Fundamental rights of migrants or persons with a migration background have different functions: they may be interpreted as defending rights, sharing rights and participatory rights. Basically and from the civil-liberal tradition, human rights are barriers to defend the individual against illegitimate abridgment of individual positions - like life, liberty, freedom of expression, property - by government, later on without a statute, a law as adopted by Parliament. This status is one of the anchors of the rule of law. The migrant may defend himself against illegal deportation, detention, exploitation. He must have the right to stay in the country on humanitarian grounds, at least as long as it is decided by a fair procedure, whether this granted by the right of asylum or another secure status. This status (status negativus, man versus the state) includes access to courts.

The body can live on rights. In fact, the rights of life, liberty, good health - the right to survive - generate entitlements to share state offerings in subsistence, food, housing, security, information, and education from the beginning of being in a country as a migrant. How can one survive in an unknown environment without a chance to be taught the basics of the language? How can one survive without being granted a chance to find a paid job? Article 8 of the European Convention of Human Rights enshrines a facet of that basic sharing right: "Everyone has the right to respect for his private and family life, his home and his correspondence." These rights may be put together in the status positivus.

Finally, an underlying legal instrument to help people with a migrant background to participate in civil and political life is required to grant migrants participatory rights (status activus). Basic liberties for all encompass a right to petition, to express oneself, to assemble, to demonstrate, to found an association, and to join a trade union or a political party. Not only must a country grant access to the voluntary civic sector, but - in the long run it must allow for access to nationality: to become eligible to be in a condition to fulfil the requirements for naturalization, to enjoy - for that purpose - a secure status.
Until now European Member States have operated a diversity of regulations for the legal status to stay, and ultimately for the acquisition of citizenship. Some countries are more restrictive, some more liberal. Just as an example - without any evaluation - the situation in Germany is as follows:

- a migrant crossing the border illegally starts with toleration of stay, which means temporary prohibition of deportation;

- that person may receive a time-limited permission of stay, during which he/she can work;

- after seven years he/she may be granted a permission of establishment, ie to start a business;

- finally, after eight years, he/she may apply for naturalization.

Those applying for naturalization must pass a language test, and display basic civic knowledge along with the independent capacity to finance their existence. Germany changed the principle of naturalization some 20 years ago from the descendent principle (ius sanguinis) to the territorial principle (ius soli), so that anyone with a migrant background born on German territory has an easier chance to gain citizenship than before.

The country is not in favour of dual or multiple nationality, and therefore an application for citizenship requires the renunciation of all former nationalities. At the age of 18 years, when legal capacity begins, a person who still has double nationality has to choose which one to opt for. There are exceptions in hardship cases a factual integration is accepted, and of course there is a rather difficult, but frequently used, asylum procedure on the grounds of political persecution. In Germany, as in most European countries, participatory rights are taken very seriously. Participation at all levels, mobilisation, and finally representation are the king's way to integration.

The UN General Assembly in 1986 adopted the declaration on the Right to Development. Article 1 defines this right as an unalienable human right by virtue of which every human being and all peoples are entitled to participate in, and contribute to and enjoy, cultural, social and economic development in which all human rights and fundamental freedoms can be fully realised. This declaration constitutes a major step towards the conceptualization of a third generation of human rights, after the first generation, the liberal rights, and the second, covering social and participatory rights.

This description of the various legal instruments of human rights on three levels - international, national, regional - raises the question of whether we face an inflation of rights, ie that the body of law has become overcomplex, redundant, and lacking in transparency. It is true that an individual seeking protection against illegal state action may find himself in a sort of "Bermuda Triangle" between his national Constitutional Court, the European 
Court of Justice in Luxemburg and the European Court of Human Rights in Strasbourg. For example, 6,000 constitutional complaints a year reach the German Federal Constitutional Court in Karlsruhe, 3,000 of which are carried further to Strasbourg.

When considering the issue of "overflow", the following three factors should be borne in mind. First, the elements of all instruments of fundamental rights are similar, if not the same: dignity of the person, freedom, equality, freedom of creed and belief, etc. The methodology used to interpret the body of these rights is comparable, and the instruments strengthen instead of weaken each other. Second, a wide range of nations is subject to the courts' adjudication. Countries like Armenia and Azerbaijan must defend their actions, as well as Poland and Denmark. And third, the national courts have developed interpretations which respect the approaches of higher courts. For example, the German Federal Constitutional Court in Karlsruhe does not interfere in European human rights cases, "as long as the European Court of Justice applies human rights in the same manner as the Karlsruhe Court would do.”

The judges in Karlsruhe look at decisions of the Strasbourg Court as "pillars of interpretation of fundamental rights" and interpret national human rights "in the light of Strasbourg's understanding of them." By this method the national court in Karlsruhe treats the European Convention of Human Rights as if it were on national constitutional level, although in fact it has only the strength of statutory law.

\section{Challenges and possibilities}

The three highest barriers for integration of people with a migrant background are as follows:

- acquisition of citizenship is difficult;

- opportunities for political activities are limited;

- for children, wherever they come from, opportunities for a common and successful education are insufficient.

Integration policy changes in small steps could have important effects for lives of individuals. This is the main reason why we have to take integration policy very seriously.

Challenges, even dangers, to the coherence of societies in our cities are posed to varying degrees by the formation of parallel societies. We observe violence involving mainly, although not only, young persons, caused by unemployment and insufficient enforcement of schooling. We encounter discrimination, racism (including antisemitism), xenophobia, and dangerous fundamentalism fed by the explosive situation in the Near East. Trafficking has emerged as a global theme, contextualizing migration within a framework of combating organized crime and criminality, subordinating human rights protection in order to pursue anti-crime measures. Sometimes honest language is missing. The Chairman of the Green Party wants to cope with shortage of labourers with expert knowledge. One tool should be granting double citizenship. Here one should not use the rhetoric of "mercy of naturalization" but honestly point towards "glaring national interests."

Sometimes migration policy suffers from direct political influence exerted by foreign countries. If the Prime Minister of Turkey on visits to Germany repeatedly addresses people with a Turkish migration background as distant "outposts", he undermines the policy of encouraging them to seek nationalization.

Where do we stand? The Migrant Integration Policy Index (MIPEX, No III of 2011), established by the British Council and an International Migration Policy Group, uses seven factors to measure the success of integration:

- mobility of labour market;

- family reunion;

- education

- political participation;

- permanent stay in the country;

- possibility to gain citizenship;

- anti-discrimination policy.

The study ranks country success on a scale from 1 to 100 in six groups, like school notes:

1. very unfavourable (0 points)

2. unfavourable (0-20 points)

3. unfavourable tendencies (20-40 points)

4. halfway favourable (40-60 points)

5. favourable tendencies (60-80 points)

6. favourable (80-100 points)

Poland received 42 points and Germany 57 (both halfway favourable). Sweden received 83, Portugal 79 and the USA 62 (all favourable tendencies).

All countries, having analysed the challenges and dangers of failing integration, strive to improve the possibilities. This is a task for society and government, in that order. Employment, schooling, language-education are of prevailing importance. Competition in sports and civic groups are encouraging indicators of cohesion. Cultural diversity dominates more and more local events. Institutions such as Amnesty International, and various internet networks, are indispensable. The author is a member of "Foundation for politically persecuted persons" in his home city of Hamburg. Journalists, poets, artists and others - with their families - are offered a stipend to live in Hamburg, to breathe freely, to do what they cannot do at home. There are possibilities. Public opinion and public opinion-makers are important factors in combatting discrimination and xenophobia.

There appears to be agreement in all European countries on some basic requirements within societies and politics 
for furthering integration. Policy must be bottom-up, not top-down. Integration has to revolve primarily around the hearts and minds of individuals, not of institutions and governments. However, institutions can help, support and encourage. On the national level, language capacity is of primary importance. Without language and communication, cultural, civic and political participation cannot take place. All public institutions must be called upon to support individuals and families. For that we need not only schools and kindergardens, but in addition a culture of "honorary office" centred around the activities of individuals, associations, and migrants' groups. The state must provide for the strict implementation and enforcement of the rule of law in areas such as honour killings, forced marriages, trafficking and prostitution.

A national policy for asylum, aliens, and migration is no longer sufficient. Like with all European policy fields, including Schengen, we need a clear policy of public order, transparency, legal reliability, and burden-sharing. The first steps have been taken, but the next ones need to follow.

Finally, migration, non-discrimination and integration are an international policy programme in a globalized, "migrating society." We need an international system for the collective maintenance of peace. This requires effective sanctions against countries which violate fundamental rights and force their citizens to flee and escape. And then we have to widen the perspective in order to avoid economic migration, very often due to growth of population and unfortunate developments of environment.

\section{Dignity, freedom and equality - democracy}

The core of human rights, which we analysed in the context of migrants and integration, are dignity, freedom and equality, namely non-discrimination. Freedom and equality are the source of democracy. I believe that the free democratic order of societies and states will be the form of government for the future. It will grow and spread. Some politicians and scholars advocate the notion of human rights, as described here, as being just one of multiple, pluralistic understandings of human rights.

Take, for example, China's understanding of human rights. China still has an authoritarian system of government, which seems to be slowly opening up to the world. If you talk with Chinese students of law and political science, be it in Wuhan, Nanjing or Beijing, you will discover that they have the same perception of freedom of speech, profession, mobility etc and also hope to have a chance freely to develop their capacities. Some politicians and scholars are of the opinion that the Muslim perception of human rights is different from ours. It is true that most parts of the Muslim-Arab world did not have a chance to undergo a period of enlightenment, as European countries did in the late 18 th and early 19 th century. Some imams noticed that, and support Islamic research and teaching at European universities, not at least for the purpose of educating teachers of Islam at schools. As far as the European tradition of understanding human rights is concerned, we might be well advised to adhere to the four columns of European culture, which are Greek philosophy, Roman law, Judaic-Christian religion, and enlightenment. As Article 2 of the Lisbon Treaty puts it:

"The Union is founded on the values of respect for human dignity, freedom, democracy, equality, the rule of law and respect for human rights, including the rights of persons belonging to minorities. These values are common to the Member States in a society in which pluralism, nondiscrimination, tolerance, justice, solidarity and equality between women and men prevail."

Professor Dr Ulrich Karpen

Law Faculty, University of Hamburg

\title{
Articles for Amicus Curiae
}

Amicus Curiae welcomes contributions, which should be accompanied by the name and contact details of the author. The journal publishes articles on a wide variety of issues, ranging from short pieces of 700-1,200 words and longer articles of 4,000 words of so (the upper limit can be extended where appropriate). Articles should be written in an informal style and without footnotes.

\author{
Anyone interested in submitting a piece should email Julian Harris \\ (julian.harris@sas.ac.uk).
}

